\title{
Information Flows Management as a Way to Overcome "Puberty Challenges" of a Small Enterprise
}

\author{
E. Litau \\ ITMO University \\ 197101, Kronverkskiy pr., 49, lit. A \\ Saint-Petersburg, Russia \\ +79219640265 \\ science@blcons.ru
}

\begin{abstract}
The objective of the study was to address key issues of smallsized firms' development to identify the reasons why many small enterprises are incapable of growth and to move into a mediumsized business. We present the concept of the Information Problem which is an indicator of the enterprise growth and at the same time an obstacle for its further development. We show that the prompt identification and solution of the problem would enable many small enterprises to increase the scale of operations and build efficient management systems.

The findings justify the primary importance of the fundamental laws of human psychology in any business transition phase. They also provide an improved understanding of small enterprises' development and factors that contribute or impede their success. We also present a possible methodology that helps to meet the "puberty challenges".
\end{abstract}

\section{CCS Concepts}

- Applied computing $\rightarrow$ Law, social and behavioral sciences $\rightarrow$ Economics

\section{Keywords}

Entrepreneurship; entrepreneurs; small enterprises; information management

\section{INTRODUCTION}

Perhaps the most severe transformation the industrialized countries have undergone is the current one, caused by the increased importance of information and knowledge. For many years now, knowledge intensification and information overload have been widely considered to be the most important challenges with which modern business is confronted.

The issues are of special importance for small-sized businesses and startups which have to navigate the information sea and show flexibility in order to stay competitive and not drop out of the race. Over the last years, smaller entities have been at the center of public discussions, as they are found to play the key role in economic development and job creation [1, 7, 10, 11]. This thesis

Permission to make digital or hard copies of all or part of this work for personal or classroom use is granted without fee provided that copies are not made or distributed for profit or commercial advantage and that copies bear this notice and the full citation on the first page. Copyrights for components of this work owned by others than ACM must be honored. Abstracting with credit is permitted. To copy otherwise, or republish, to post on servers or to redistribute to lists, requires prior specific permission and/or a fee. Request permissions from Permissions@acm.org.

ICBIM'18, September 20-22, 2018, Barcelona, Spain.

(C) 2018 Association for Computing Machinery

ACM ISBN 978-1-4503-6545-1/18/09 ...\$15.00.

DOI: http://doi.org/10.1145/3278252.3278259 can be traced back to David Birch, who studied high-growth firms which he called "gazelles" $[3,16]$. However, although Birch and other economists suggest that growth is paramount to entrepreneurial success, most companies do not grow. In fact, only about $4 \%$ of all businesses are able to show sustained growth and exert a deep influence on macroeconomic outcomes [3].

The paper introduces the Information Problem concept, shows the importance of internal factors in small enterprise development and presents the methodology that helps to meet the challenges of growth.

\section{THE DEVELOPMENTAL APPROACH TO THE STUDY OF ENTERPRISES}

Recognizing the importance of small businesses for economic growth prompts national governments to establish policies that intend to boost their potential. The policies include a wide array of support programs, tax incentives and other benefits. However, with all the heavy investments into such programs, governments do not necessarily achieve the goal. There is increasing empirical evidence to suggest that these attempts sometimes produce even counterproductive results for high-growth entrepreneurship [17].

This indicates that the process of small enterprise development is not as dependent on external factors as is commonly believed and that the reasons preventing the progress are of internal rather than external nature. A transition of a small enterprise into a mediumsized is akin to the adolescent period for people. Many, if not all, face "puberty" difficulties at a certain phase of maturation.

At every stage of life, one encounters a particular problem inherent to this period, but it is the pubertal period that we pay enormous attention to as it determines the whole subsequent life of the individual. In terms of enterprise evolution, the move from a small into a medium-sized business seems to be the most significant period, as it sets up foundations for the firm's successful development. The enterprise experiences transformation from an informal structure into a formal organization. That is why the study of factors contributing to the success of this process (as well as the ones impeding it) is extremely important.

\section{THE ENTREPRENEUR'S COGNITIVE LIMITATIONS}

Since the 1980s researchers have used organizations as the unit of analysis in entrepreneurship studies and the entrepreneur as the actor who enables the existence and growth of the organization [7]. Based on this approach, they have focused on personality traits that distinguish successful entrepreneurs from the herd. However, researchers often ignored the influence of attributes and patterns inherent to each individual due to the fundamental laws of human psychology. Yet, it seems that these primary laws, abilities and 
limits (such as the human brain's memory-storage capacity and the capacity to perceive and process information) directly affect entrepreneurial success, i.e. the ability of "gazelles" to maintain a given rate of growth and move into the category of medium and large companies.

According to George A. Miller, who uncovered the basic patterns of perception and processing of information, the human brain's working memory is capable of holding and processing only seven plus or minus two "chunks" of information (the famous Miller's magical number) without error [4, 9]. In his experiments Miller attempted to evaluate and, more importantly, to measure the amount of information that can be perceived and transmitted without quality loss. He assumed that if the human observer is a reasonable kind of communication system, then with the increase in the amount of incoming information the transmitted information will increase at first and will eventually level off at some asymptotic value. Milled called this asymptotic value the "channel capacity": it represents the greatest amount of error-free information that a person can transmit.

We consider the scientific value of these experiments to stem from the fact that one of the goals of the study was to establish units for measurement of the transmitted information. As this unit of measurement, Miller proposed to use the binary digit, or bit [4].

The conclusion that human capacities of information perception and processing are limited cannot be recognized significant due to its obviousness. However, the fact that these limitations can be quantitatively measured suggests that our management capacities are determined not only by our individual characteristics, but also by the fundamental laws of human psychology. Considering that these can be described mathematically, the finding is of apparent practical value. This is because, drawing on the assumption of the entrepreneur's limited capacities to process information, we can identify objective patterns of small enterprises development and enhance entrepreneurial performance.

\section{INTRODUCING THE INFORMATION PROBLEM CONCEPT}

To get an idea of how basic psychophysiological characteristics of the entrepreneur, and, in particular, the limitation deduced by Miller, influence the performance of a small enterprise, one should trace its life cycle.

Most small enterprises start out as a one-man band with the entrepreneur handling all its operations single-handedly. At the initial stage, all daily activities tend to be at the sole discretion of the founder [12]. Being the business owner, its manager and often employee, the entrepreneur is directly involved in all routine processes of his or her venture. This can be called centralization of information flows.

In the course of business development, though, information processing issues arises, caused by every person's limited capacity to perceive, analyze and synthesize information. In other words, entrepreneurial manager is faced with what we call the Information Problem. The Information Problem concept relies on the following assumptions:

1. The entrepreneurial ability is a mix of special personality traits, a "fourth factor in production" [15]. Admittedly, the existence of such traits does increase a person's chances of establishing a successful business and can be seen as a kind of a gift [5].
2. The amount of information a person can process and remember is limited by the volume of immediate memory. This suggests that, as small businesses develop, they face increasingly large information flows that cannot be efficiently processed due to certain limitations built in the human brain.

3. Entrepreneurial process is inevitably characterized by an increase in the number of incoming information flows as well as in information content of each distinct flow.

It should be highlighted that the term "Information Problem" is not found in academic writing and was proposed by the author for the purpose of applying a new approach to the issues of small enterprises development. The advantage of the approach is that, in spite of variance in entrepreneurs' personality characteristics and environmental factors (state of market, etc.), it enables one to decipher objective, generalizable patterns of development inherent to small-scale developing enterprises, regardless of individual conditions of their activity.

If we look at the small enterprise as a system where each process or task (e.g., relations with suppliers and customers, advertising, production, etc.) is an information flow, we will see that at the early stage of development all flows inevitably pass through the entrepreneurial manager. It is impossible to deny that continuous development of a small enterprise is characterized by increasing information flows. As the enterprise grows, many changes occur. The scale of operations increases: the number of orders and the volume of purchases grow, production expands, the staff size increases, and the tasks become ever more challenging. This implies complication and a significant increase in the number of information flows. Apart from that, the situation remains the same, with almost all flows, regardless of their urgency and importance, passing directly through the entrepreneur. Information overload eventually takes a toll. At a certain stage, the volume of incoming information starts to well exceed the entrepreneur's ability to perceive and process it.

The entrepreneur comes close to the boundary of his or her "channel capacity" and reaches a point when confusions begin to occur. Information overload leads to the ignorance of important data, inaccurate processing and procrastination and thereby hinders performance. In addition, the more information an individual should process, the more the cognitive system becomes limited to the left brain hemisphere. The part on the right side is suppressed, which hampers the ability of creative thinking [14]. The entrepreneur continually experiences time shortage and is unable to fully control business operations. With more and more failures to process incoming information and make timely and proper decisions, he/she begins to hamper the development of the company. With no appropriate redistribution performed, the business, being suppressed by the entrepreneur him/herself, begins to stagnate and lose competitiveness and cannot further develop. To put it otherwise, it is not so much external factors (such as deficiencies in government policies to support SMEs, high cost of loans, sales challenges, etc.) that impede growth, but rather a failure to address the Information Problem.

\section{THE CHALLENGES OF INFORMATION FLOWS REDISTRIBUTION}

Thus, the enterprise development is inevitably characterized by increase in the number of incoming information flows as well as increase in information content of each distinct flow (in other words, a growing number of bits). 
A natural wish to solve the Information Problem, i.e. to redistribute information flows in a smart way, brings about the need to delegate responsibilities, which, in turn, results in structural changes in the management system. In a sense, the building of enterprise management structures is a form of information recoding. A management structure arises as an objective necessity of a developing small enterprise: the entrepreneur has to use hired labor and redistribute information flows as to achieve an appropriate level of comfortable perception. It would be fair to say management structure building is a process of information segments formation. This process continues until sufficiently small number of units develops that we are able to correctly process, transmit and transform into management decisions.

In practice, the process of information flows redistribution is expressed in the entrepreneur delegating some tasks and responsibilities to other individuals (employees), which subsequently results in formation of a management structure typical of a developing small enterprise. As long as internal and external information flows pass directly through the sole subject - the entrepreneur, the enterprise has no potential of development.

Management processes, financing methods, staff number, revenue size, balance sheet assets and other criteria that distinguish small enterprises from medium-sized and large ones evolve as the business develops. It is the Information Problem that is a prerequisite for the emergence and development of these attributes, because the information flows redistribution leads to a more complex enterprise structure and an increase in both material and labor resources. Thus, the increase in information flows appears to be the source of both qualitative and quantitative changes occurring as a small enterprise develops and moves to the next segment (medium-sized business). The development of all said attributes is a result of this underlying cause.

We can therefore look at the Information Problem as the objective prerequisite indicating the small enterprise development. When the problem is identified, one has to initiate information flows redistribution, as otherwise the enterprise's subsequent development would be impossible. The moment is inevitable, when the entrepreneur starts to use employees' labor to redistribute a part of information flows and thus reduce the information load to an acceptable level.

\section{THE PROPOSED SOLUTION}

More often than not, information flows redistribution, and accordingly the management structure (trans)formation, at the stage of early business development is an intuitive and even chaotic process. Changes are targeted at short-term needs and do not involve professional management tools and technologies. Therefore, the main method of addressing the Information Problem is typically by trial-and-error.

Yet, it should be noted that, in the course of development, small enterprises build up financial and intellectual resources that, when used correctly, allow to create information processing system, which may subsequently serve as a basis for a management structure that would be effective for this specific business.

One of the possible solutions could be to use specialty software tools such as the one that we developed to implement the proposed approach. The design specification included the following requirements:
1. Simplicity and visual clarity.

2. Practical focus (the software should give a motivational "push" that would induce the entrepreneur to produce qualitative structural changes, rather than just provide him/her with a list of general recommendations).

3. High speed of analysis (as when the Information Problem arises, time is the tightest resource).

4. Iterative character (given limited material resources, the entrepreneur cannot eliminate all bottlenecks in key business processes at once; transformation must be carried out in stages, from higher to lower priority).

5. Easy applicability and affordability.

6. Clearly defined measures.

The developed Smart Management of Information Flows tool (SMIF) draws on the Information Problem concept and takes account of external and internal factors affecting an enterprise and generating respective information flows. The problem-solving algorithm consists of the following steps: making a "snapshot" of information flows, their quantitative evaluation in terms of two dimensions (see below), analysis of the findings, and subsequent redistribution of information flows. The iterative cycle is to be repeated as the company evolves.

\section{The analysis of data flow}

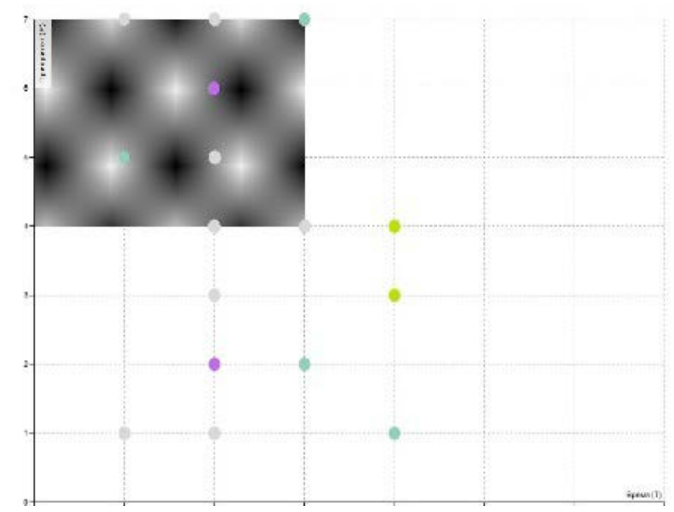

The diagram of the user`s data flow

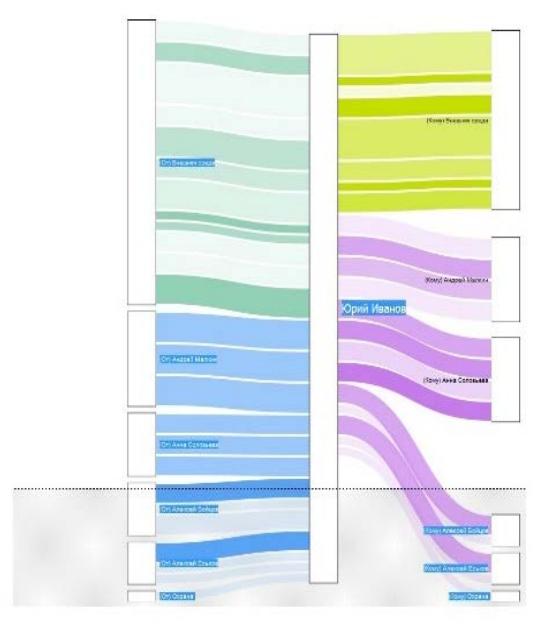

Figure 1. Information flows "passband" and an entrepreneur's information flows diagram: the SMIF web 


\section{Figure 1 legend}

$\begin{array}{ll}\text { Y axis } & \text { Priority (P): } 1 \text { to } 7 \\ \text { axis } & \text { Time (T): } 1 \text { to } 7 \\ \text { The passband range } & \text { Several information flows } \\ & \begin{array}{l}\text { External incoming information flow } \\ \text { External outcoming information flow }\end{array} \\ \text { Internal incoming information flow } \\ \text { Internal outcoming information flow } \\ \text { The wider is the information flow, the more } \\ \text { time the entrepreneur needs to process it. } \\ \text { The information flow source (from) } \\ \text { thestination (to) } \\ \text { the entrepreneur. }\end{array}$

The tool requires information flows to be measured by each entrepreneurial manager in terms of time $(\mathrm{T})$ and priority $(\mathrm{P})$. The estimation of time consumption does not require mathematical accuracy as long as it is aligned with subjective perception of the entrepreneurial manager. Prioritization of information flows might as well be intuitive or might depend on certain criteria. Combining these two dimensions - time consumption estimates and priority level of each task - gives a comprehensive view of information flows at an enterprise.

It seems reasonable for the entrepreneur to first address information flows with the highest priority and the least processing time. We assume an information flow to be "appropriate" if its time value is $1-4$ and priority level is 4-7 (both estimates are expressed on the scale from 1 to 7). We refer to this range of values as a "passband" (see Figure 1).

This approach to information flows management rests on what can be called "elimination principle" implying that information flows that do not fall into this range are excluded from the entrepreneur's scope of decision-making due to their lower relevance, thereby freeing up more time for the most important management decisions. The flows thus excluded are subject to aggregation, categorization and further redistribution among other employees. In other words, the suggested method of flows redistribution is based on authority delegation and/or automation of the tasks that do not relate to direct enterprise management and can be performed by employees without entrepreneur's immediate supervision, whereas the most "appropriate" flows that satisfy the passband conditions require a direct involvement on the part of the entrepreneur.
To pilot the proposed tool we selected 30 small and micro enterprises in the North-West region of the Russian Federation. The sample included startups and young companies as well as more established enterprises operating in several sectors of service industry. The same location ensured that enterprises were exposed to equal political, economic, geographic, socio-cultural, environmental and other external influences; they had almost the same funding options available and their owners served as top managers.

The implementation of the developed tool in the surveyed companies helped their executives make timely decisions regarding necessary structural changes and enabled a more systematic and meaningful authority delegation process. In the course of this transformation, the entrepreneurial managers started to develop a consistent view of enterprise management and to recognize a need for business processes reorganization. This enabled the enterprises to promptly respond to market needs and ensured greater competitiveness.

The Podpisnyje Izdanija ("Subscription Editions") bookstore represented one of the most prominent success stories. It should be noted that the retail book industry in Russia is going through a major crisis. The last 5 years saw a 12\% drop in book sales. However, the revenue of the named store increased greatly over the same period. Within a short time, the up-and-coming entrepreneur who had took the reins in 2012 was able to build a new team (the headcount increased from a handful of employees to 25) and optimize business process performance. The entrepreneur disengaged himself from excessive information flows associated with routine operating activities, which enabled him to focus on more value-adding creative tasks related to development and production of tasteful, but inexpensive souvenirs and gifts. The launch of the new line of business accounted for the rapid growth in revenue and offered the small individual retailer opportunities to penetrate new regional markets. The revenue increased by $49.7 \%$ in 2015 and by $68.9 \%$ in 2016. Another example is the Probka ("Cork") restaurant founded by a famous chef in 2000. The early success of the business led to an expansion, with 7 more projects launched over the next 10 years. Although employee engagement was always a priority for the entrepreneur, he eventually came to a point where the task of managing an increasingly large team became too overwhelming. He thus faced the Information Problem. Financial performance declined accordingly: the network experienced consistent losses for 4 years since 2010. In 2014, the founder made a key decision to withdraw from operating control of all restaurants at once, built a high-quality management system and focused on managing a single favorite restaurant. The company soon achieved break-even and started making money. The revenue increased by almost $100 \%$ in 2015.

Out of 30 studied enterprises, 26 successfully overcame the crisis by timely introducing of a new management system and maintaining the growth dynamics. The remaining 4 enterprises went out of business, and their founders have no intent to continue an entrepreneurial career.

Importantly, the methodology was able to take account of individual characteristics of the enterprises and demonstrated that a failure of the 4 companies from the sample had been determined by their top managers' personality traits. The software can be successfully implemented provided that entrepreneurial managers are sufficiently motivated to move from small to medium-sized company and comply with all the steps envisaged by the proposed algorithm. 


\section{CONCLUSIONS}

In the course of a new venture development, the entrepreneur has to deal with increasingly large information flows ultimately reaching appoint at which the information cannot be processed without quality loss due to limitations built into the human brain. Faced with these "pains caused by the growth", entrepreneurs are in desperate need of information management tools. In other words, the small enterprise transformation into a medium-sized company, irrespective of the industry, is preceded by emergence of the so-called Information Problem. This indicates that the process of small enterprise development is not as dependent on external factors as is commonly believed and that the reasons preventing the progress are of internal rather than external nature.

Due to limits in human capacity to perceive and correctly process large amounts of information, entrepreneurs need to free up their "information space" to make the management process effective and enable the company to develop and enhance the scope of activities. This is achievable only by means of reprocessing (recoding) of information flows related to business operations. The effectiveness of such redistribution largely determines a small enterprise development and the chances of its transition into the category of medium-sized businesses.

One of possible solutions could be to use specialty software such as the software tool proposed by the author for small enterprise information management. The tool allows for efficient redistribution of information flows and, thereby, enables entrepreneurs to cope with the challenges of growth. The implementation and application of the product does not require significant intellectual and financial resources and hence is affordable to almost any enterprise. Therefore it could become the "penicillin" for potential "gazelles" to overcome the crisis of transition and continue successful development.

We foresee future software products to be developed that could capture cognitive aspects of entrepreneurial activity in a more fine-grained way. Special hopes are pinned on insights from neuroscience [6]. This field did not even exist 20 years ago, but thanks to technological advancements, it has become one of the fastest growing areas $[2,8,13]$. Considering that the essence of entrepreneurship lies in entrepreneurial thinking and that entrepreneurship performance is determined by a wide range of cognitive tasks (attention, memory, problem-solving and other activities having to do with acquisition, processing and use of information), the discipline seems to be the most fitting contender for helping entrepreneurs out of "puberty challenges".

\section{REFERENCES}

[1] Audretsch, D. 2012. Determinants of High-growth Entrepreneurship. Report prepared for the OECD/DBA International Workshop on High-growth Firms: Local Policies and Local Determinants, Copenhagen, 28 March.

[2] Binder, J. K., McBride R., Sud A., Wuebker R. J. And Pereira D. 2015. Is "Neuroentrepreneurship" Worth Pursuing? Academy of Management Annual Meeting Proceedings, 1.
[3] Birch, D. 1987. Job Creation in America: How our Smallest Companies Put the Most People to Work, New York, Free Press.

[4] Cowan, N. 2015. George Miller's magical number of immediate memory in retrospect: Observations on the faltering progression of science. Psychological Review, 122, 536-541.

[5] Gardner, H. 2011. Frames of Mind: The Theory of Multiple Intelligences. Basic Books.

[6] Handbook of Research Methodologies and Design in Neuroentrepreneurship. Edited by M. Day, M.C. Boardman, N. F. Krueger. Edward Elgar Publishing, 2017.

[7] Janczak, S., Bares, F. 2010. High Growth SMEs:The Evolution of the Gazelles and Some Evidence from the Field. HEC-Montreal Working paper $n^{\circ}$ : 2010-01, April 2010.

[8] McMullen, J. S., Wood, M. S., and Palich, L. E. 2014. Entrepreneurial cognition and social cognitive neuroscience. Handbook of Entrepreneurial Cognition, 316-363.

[9] Miller, G. A. 1956. The magical number seven, plus or minus two: some limits in our capacity for processing information. The Psychological Review, 63, 81-97.

[10] OECD, 2016, Entrepreneurship at a Glance 2016, OECD Publishing, Paris.

[11] OECD, 2017, Enhancing the Contributions of SMEs in a Global and Digitalised Economy. Retrieved April 10, 2018 from https://www.oecd.org/mcm/documents/C-MIN-2017-8EN.pdf.

[12] Penrose, E. The theory of the growth of the firm: Oxford University Press, 2009.

[13] Pérez-Centeno, V. 2017. It takes three to tango: Brain, cognition and entrepreneurial enhancement. Working Paper, Institut für Mittelstandsforschung (IfM), Bonn.

[14] Sander F., Janovsky, J. 2016. Globalization as a risk factor for creativity and innovativeness. Ekonomski Vjesnik, Vol. 29, Iss $1,177-192$.

[15] Schumpeter, J. A. 1911/1934. The theory of economic development. Cambridge, MA: Harvard University Press.

[16] Tachiki, D. 2013. High growth innovative enterprises: A Research Note on Japan. Tamagawa University, Faculty of Business Administration Bulletin, 21, 61-75.

[17] Van Stel, A., Storey, D. J., and Thurik, A. R. 2007. The effect of business regulations on nascent and young business entrepreneurship. Small Business Economics, 28(2-3), 171186. 